\title{
THE STRATEGIC USE OF TEMPORARY WORK - EVIDENCE FROM GERMANY
}

\author{
Christian Lehmann
}

dx.doi.org/10.18374/JIBE-13-1.7

\begin{abstract}
Temporary work is one of the fastest growing employment forms in Western Europe. On the firm level, research on temporary work focuses on environmental and structural characteristics as the main predictors of temporary work. This paper addresses the strategic use of temporary work. It is assumed that the appointment of temporary workers does not happen occasionally, but rather strategically, as part of a firm's HRM strategy. With data from 235 firms in the German manufacturing industry, we extract two meta-motives of the use of temporary work and identify four ideal-typical strategies: a strategy of ad-hoc compensation, an HRM outsourcing strategy, a strategy of HR flexibilization, and a dual strategy, combining HRM outsourcing and HR flexibilization. We further show (a) that each strategy is associated with a specific pattern of use of temporary work, (b) that the four strategies show different relations to other instruments of employment flexibilization, and (c) that each strategy offers different ways to improve a firm's performance.
\end{abstract}

Keywords: Temporary Work, Employment Flexibility, Human Resource Management, Firm Performance 